\title{
Kencenderungan Kelompok Muda Untuk Berwirausaha Berdasarkan Faktor-faktor Personal
}

\author{
Ratna Muljani Santosa ${ }^{1}$ \\ Universitas Bunda Mulia \\ Email: rsantosa@bundamulia.ac.id \\ Michael Christian² \\ Universitas Bunda Mulia \\ Email: michaelchristianid@gmail.com
}

\begin{abstract}
One of the acceleration of a country's economic growth can be supported by the participation of creative and risk-taking labor force groups. However, sometimes the courage does not run in balance with creativity. Therefore, the tendency of younger groups to start independent businesses is often constrained by internal factors such as personal principles and unwillingness to take risks. Personal attitudes will depend on individual perceptions formed through life experience, learning, observation of others and other things. This study aims to see the entrepreneurial intention by the factors of propensity to act (creativity, self-control, norms and attitudes) of young groups to act in realizing independent entrepreneurship. Quantitative research with questionnaire instrument using the Statistical Package for Social Science (SPSS) 22 application, this study used multiple regression analysis on the error rate of 5\%. This research explains about partial entrepreneurship intention by individual creativity in young group. On the other hand, the entrepreneurial intention partially is not known by social norms and the courage to take risks in young groups. Subsequent studies may use more sample quantities to explain the likely outcomes. In addition, further research can also use a description of the choices on the item being asked to give more precision to the factor of courage in taking the risk of entrepreneurship.
\end{abstract}

Keywords: entrepreneurship, propensity to act, intention

ABSTRAK: Percepatan pertumbuhan perekonomian suatu negara salah satunya dapat didukung dari peran serta kelompok angkatan kerja yang kreatif dan berani mengambil risiko. Namun demikian tidak jarang keberanian tidak berjalan seimbang dengan kreativitas. Oleh karena itu, kecenderungan kelompok muda dalam memulai usaha secara mandiri tidak jarang terhambat faktor -faktor internal seperti prinsip personal dan keengganan untuk mengambil risiko. Sikap personal akan bergantung pada persepsi individu yang terbentuk melalui pengalaman hidup, proses belajar, pengamatan terhadap orang lain maupun hal lainnya. Penelitian ini bertujuan untuk mengetahui apakah keinginan berwirausaha dipengaruhi oleh faktor-faktor kecenderungan (kreativitas, kendali diri, norma sosial yang mengikat, dan pengambilan risiko) kelompok muda untuk bertindak dalam mewujudkan berwirausaha secara mandiri. Penelitian kuantitaif dengan instrumen kuesioner ini menggunakan aplikasi Statistical Package for the Social Sciences (SPSS) 22, penelitian ini menggunakan analisis regresi berganda pada angka galat sebesar 5\%. Penelitian ini menjelaskan bahwa keinginan berwirausaha secara parsial dipengaruhi oleh kreativitas individu pada kelompok muda. Di sisi lain, keinginan berwirausaha secara parsial tidak dipengaruhi oleh norma sosial dan keberanian dalam mengambil risiko pada kelompok muda. Penelitian selanjutnya dapat menggunakan jumlah sampel yang lebih banyak untuk menjelaskan hasil yang mewaikili. Disamping itu, penelitian selanjutnya juga dapat menggunakan deskripsi pilihan pada item yang ditanyakan untuk memberikan ketepatan lebih pada faktor keberanian dalam mengambil risiko berwirausaha.

Kata Kunci: wirausaha, kewirausahaan, kencenderungan, keinginan

PENDAHULUAN

Latar Belakang

Percepatan pertumbuhan perekonomian suatu negara dapat didukung salah satunya dari peran serta kelompok angkatan kerja yang memiliki keterampilan dalam menjalankan aktvitas ekonomi suatu negara (Malik, 2015). Berdasarkan laporan National Academy of Sciences, kelompok muda di negara-negara berkembang mengalami peningkatan signifikan (Furstenberg Jr, 2010). Kelompok ini turut memengaruhi globalisasi sosial dan ekonomi yang berkembang pesat (Stromquist \& Monkman, 2014). Perkembangan tersebut salah satunya berkaitan dengan isu dunia usaha dan tingkat kesempatan dan penyerapan kerja (Gonzales, 2011). Keadaan ini sering dilihat di negara-negara berkembang sebagai dampak dari pergeseran demografi (Alves, Cavenaghi, \& Martine, 2013).

Berkaitan dengan penyerapan tenaga kerja, upaya ini dapat didukung dengan 
pembukaan lapangan kerja melalui kewirausahaan. Isu kewirausahaan bukan merupakan fenomena baru (Dana, 2011). Setidaknya terdapat 55 peneliti yang membahas mengenai kewirausahaan yang melakukan identifikasi pada konsep dan elemen yang terkait di dalamnya, dan memberikan gambaran pada konsep area yang masih perlu untuk dibahas (Lubis, 2015). Pembahasan mengenai kewirausahaan terus mengalami perkembangan seiiring dengan terus dilakukannnya penelitian di negaranegara berbeda. Pada tahun 2010, sebuah survei yang dilakukan oleh Global Entrepreneurship Motor (GEM) pada lebih dari 3.000 ahli di lebih dari 50 negara menjelaskan bahwa sebanyak 200.000 orang yang berusia 18-24 tahun secara aktif terlibat dalam upaya untuk memulai atau mengembangkan suatu usaha baru (Amorós, Bosma, Kelley, \& Association, 2011)

Kajian penelitian juga menunjukkan bahwa salah satu sasaran pengembangan suatau wilayah (kota/desa) adalah dengan menciptakan lapangan kerja dan kesejahteraan yang dapat didukung melalui mekanisme atau alat dalam bentuk kewirausahaan (Shal, Amar, Allahyari, \& Ramezani, 2016). Di sisi lain, tren aktivitas berwirausaha telah mengalami penurunan yang signifikan, tren ini juga dapat mempengaruhi kesiapan kelompok muda untuk memulai bisnis (Arrighetti, Fabio, \& Lasagni, 2014). Padahal seperti yang dijelaskan sebelumnya manfaat dari kewirausahaan dapat dilihat dari skala kecil dan besar, salah satunya seperti di Iran yang menjadi kewirausahaan menjadi sokongan penggerak pertumbuhan ekonomi (Nasirifard, Allahyari, \& Masouleh, 2015). Secara individu, kewirausahaan tidak hanya memberikan manfaat pada eksisensi pada usaha yang didirikan namun juga kemampuan pengembangan diri untuk mengatasi perubahan-perubahan yang terjadi di masyarakat (Money, 2016).

Penggabungan bentuk keinginan, perencanaan dengan visi yang jelas, dan strategi yang jelas termasuk dalam tindakan mengambil risiko (Bessant \& Tidd, 2011 hal.11) khususnya pada kelompok muda cukup sering dapat dilihat di masyarakat. Namun di sisi lain tidak jarang ditemukan karakter individu (personal) tidak seiring dengan keinginan yang menggebu pada kelompok ini. Kecemasan dan rasa kuatir menjadi lebih dominan (Hisrich, Peters, \& Shepherd, 2010, hal. 7) dibandingkan faktor lainnya. Kepercayaan diri akan kreativitas dan keberanian bertindak dalam risiko berhadapan dengan faktor norma sosial yang ada. Berdasarkan penjelasan-penjelasan di atas, perlu dilakukan kajian lebih lanjut terkait karakter personal kelompok muda dalam mempertimbangkan berwirausaha.

\section{Identifikasi Masalah}

Kelompok muda memiliki tingkat inovasi yang tinggi yang dapat dimanfaatkan melalui bentuk kewirausahaan. Kecenderungan kelompok muda dalam memulai usaha secara mandiri tidak jarang terhambat faktor -faktor internal seperti prinisp personal dan keengganan untuk mengambil risiko. Daya saing dalam kreativitas sebenarnya dapat menjadi faktor pendorong yang kuat dalam mewujudkan keinginan berwirausaha. Ide-ide kreatif yang diimbangi dengan kemampuan analisis yang tepat dapat menjadikan kreativitas yang nyata melalui bentuk usaha mandiri oleh kelompok muda. Ragam karakter personal memang tidak dipungkiri dapat menjadi hambatan baik secara langsung maupun tidak.

\section{Tujuan dan Manfaat Penelitian}

Penelitian ini bertujuan untuk mengetahui apakaa keinginan berwirausaha dipengaruhi oleh faktor-faktor kecenderungan (kreativitas, kendali diri, norma sosial yang mengikat, dan pengambilan risiko) kelompok muda untuk bertindak dalam mewujudkan berwirausaha secara mandiri. Penelitian ini secara implikasi dapat memberikan gambaran mengenai tingkat faktor-faktor kecenderungan mana yang memberikan pengaruh secara dominan dalam pengambilan keputusan untuk berwirausaha. Secara teoritis, penelitian ini memberikan dampak pada kekayaan bahasan mengenai konsep faktor penyebab keinginan individu dalam berwirausaha khususnya dalam hal motivasi kelompok muda.

\section{TINJAUAN PUSTAKA}

Kecenderungan Bertindak Dalam Berwirausaha. Setiap individu memiliki persepsi tersendiri dalam berwirausaha. Persepsi tersebut dapat terbentuk melalui pengalaman hidup, proses belajar, pengamatan terhadap orang lain maupun hal lainnya. 
Persepsi yang didasarkan dari sikap positif personal akan dapat meningkatkan keinginan untuk memulai kewirausahaan (Ahmad, Ramayah, \& Tuan Muda, 2013). Sikap personal ini akan berdampak pada faktorfaktor kecenderungan untuk bertindak dalam memulai usaha, yaitu tingkat kreativitas, kendali diri, normal sosial yang ada, dan keberanian untuk mengambil risiko.
Kreativitas Diri. Menjalankan karir melalui wirausaha dapat memberikan kesempatan kepada individu untuk menjadi lebih independen dalam melakukan inovasi dan pengembangan kerja (Ahmed, et al., 2010). Berdasarkan skala tingkat perubahan, tingkat kemampuan individu dalam melakukan inovasi dapat dilihat dari rentang perubahan inkremental hingga radikal, seperti yang dijelaskan pada gambar 1 .

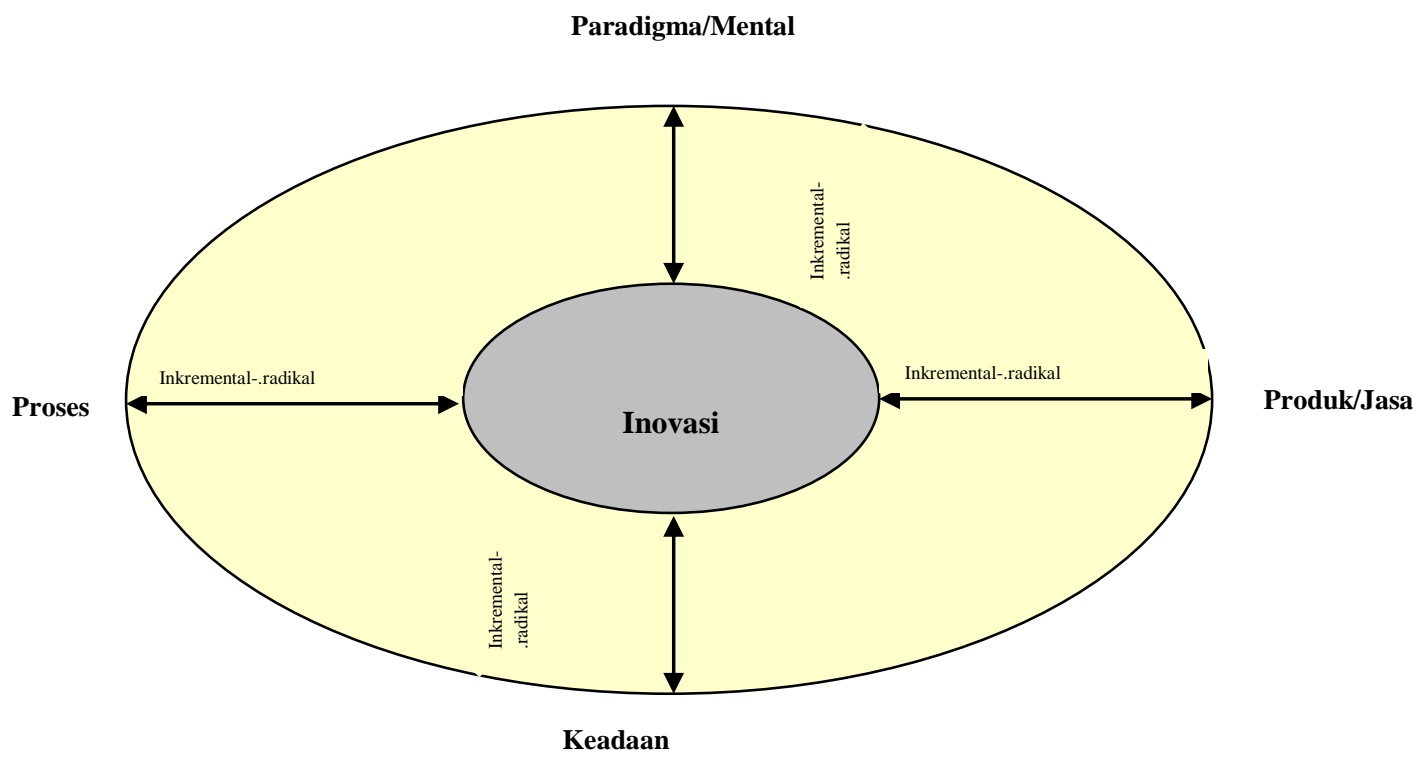

Gambar 1. Ruang Proses Inovasi

Sumber: Bessant \& Tidd, 2011

Kendali Diri. Melakukan suatu tindakan akan sangat dipengaruhi oleh daya kendali individu terhadap perilaku (Ajzen, 1991). Dalam kaitannya dengan keinginan berwirausaha, individu yang tidak memiliki kendali diri akan sulit untuk mewujudkan keinginan berwirausaha (Liñán, 2004). Bertindak secara realistis dapat membantu individu dalam memberikan sinyal kendali atas suatu keinginan. Kreativitas yang mencul tidak jarang membuat kelompok muda mengambil tindakan langsung untuk berwirausaha tanpa melakukan beberapa pertimbangan analisis lainnya.

Norma Sosial. Tidak dipungkiri bahwa faktor lingkungan menjadi faktor yang cukup vital dalam pembentukan karakter invidu khususnya terhadap kecenderungan keinginan berwirausaha. Norma subyektif yang ada turut memberikan tekanan sosial secara tidak langsung. Hal ini dibentuk karena adanya kelompok lingkungan sekitar seperti keluarga, teman, dan kelompok lainnya. Berdasarkan penelitian yang pernah dilakukan oleh Krueger, Reilly, \& Carsrud (2000) dijelaskan bahwa norma subyektif yang ada cenderung memiliki hubungan lemah terhadap keinginan berwirausaha. Begitu juga dengan penelitian yang dilakukan oleh Shook \& Bratianu (2010) yang menjelaskan pengaruh negatif norma subyektif terhadap keinginan berwirausaha pada kelompok muda. Berdasarkan hal-hal tersebut, dapat dijelaskan bahwa keberadaan norma yang ada di sekitar masih perlu dikaji terhadap ada tidaknya pengaruh pada keinginan berwirausaha khususnya pada kelompok muda. 
Risiko. Definisi kewirausahaan juga dapat diartikan sebagai karakter manusia dalam menggabungkan bentuk keinginan, perencanaan dengan visi yang jelas, dan strategi yang jelas termasuk dalam tindakan mengambil risiko (Bessant \& Tidd, 2011 hal.11). Daya kreativitas tidak jarang tidak seimbang dengan keberanian untuk mengambil risiko dalam berwirausaha. Keengganan (rasa kuatir) dalam keputusan berwirausaha cenderung muncul sebelum ide dan konsep berwirausaha dibuat. Tindakan ini mengacu pada respon penilaian terhadap keputusan atas sesuatu yang belum pasti namun memiliki kemungkinan untuk mendatangkan keuntungan (Hisrich, Peters, \& Shepherd, 2010, hal. 7). Keinginan berwirausaha dapat dijelaskan sebagai bentuk motivasi yang memengaruhi individu untuk mengejar hasil dari kewirausahaan yang dapat didorong dari efikasi diri (Hisrich, Peters, \& Shepherd, 2010, hal. 38). Usaha kecil dan menengah seperti yang dikenal, merupakan usaha yang tidak menentu yang selain membutuhkan keterampilan juga dipengaruhi faktor lain seperti kekuatan finansial, pemasaran, dan administratif (Elmansori, 2014).

\section{Operasionalisasi Peubah \& Hipotesis}

Penelitian ini menggunakan model yang digunakan oleh Ingabo (2017), dimana dalam mengukur kecenderungan bertindak pada invidu menggunakan faktor kreativitas, kendali diri, norma sosial, dan keberanian dalam mengambil risiko. Peubah operasional yang digunakan pada penelitian ini dijelaskan pada tabel 1 .

\section{Tabel 1. Operasionalisasi Peubah}

\begin{tabular}{|c|c|c|}
\hline Peubah & Dimensi/Indikator & Skala Pengukuran \\
\hline \multirow{4}{*}{$\begin{array}{l}\text { Kecenderungan Bertindak } \\
\text { Dalam Berwirausaha }\end{array}$} & Daya Kreativitas & \multirow{6}{*}{ Likert 1 s/d 5} \\
\hline & Kendali Diri & \\
\hline & Norma Sosial & \\
\hline & Keberanian Mengambil Risiko & \\
\hline \multirow[b]{2}{*}{ Keinginan Berwirausaha } & Keputusan Dalam Berwirausaha & \\
\hline & $\begin{array}{l}\text { Rencana berwirausaha dalam } \\
\text { waktu dekat }\end{array}$ & \\
\hline
\end{tabular}

Hipotesis dalam penelitian ini adalah sebagai berikut:

H1: Terdapat pengaruh secara parsial kreativitas pada keinginan berwirausaha

$\mathrm{H} 2$ : Terdapat pengaruh secara parsial kendali diri pada keinginan berwirausaha

H3: Terdapat pengaruh secara parsial norma sosial pada keinginan berwirausaha

H4: Terdapat pengaruh secara parsial keberanian mengambil risiko pada keinginan berwirausaha

Tabel 2. Penelitian Sebelumnya

\begin{tabular}{lll}
\hline Peneliti (Tahun) & Lokasi & Hasil Penelitian \\
\hline $\begin{array}{l}\text { Ahmad, Ramayah, \& Tuan Muda } \\
\text { (2013) }\end{array}$ & Malaysia & $\begin{array}{l}\text { Perilaku, normal subyektif, kendali diri, kecenderungan } \\
\text { bertindak dalam keinginan berwirausaha memiliki } \\
\text { pengaruh }\end{array}$ \\
\hline Carr \& Jennifer (2007 & US & $\begin{array}{l}\text { Perilaku berpengaruh terhadap keinginan berwirausaha } \\
\text { khususnya dalam bentuk keluarga }\end{array}$ \\
\hline Chen, Jing, \& Sung (2012) & Taiwan & $\begin{array}{l}\text { Keterbukaan pada pengalaman memiliki pengaruh pada } \\
\text { keinginan berwirausaha }\end{array}$ \\
\hline Shook \& Bratianu (2010) & Roma & $\begin{array}{l}\text { Efikasi diri dan daya bersosialisasi memiliki pengaruh } \\
\text { secara positif terhadap keinginan berwirausaha }\end{array}$ \\
\hline
\end{tabular}

Sumber: data primer yang diolah peneliti, 2017
H5: Terdapat pengaruh kreativitas, kendali diri, norma sosial, dan keberanian mengambil risiko secara bersama pada keinginan berwirausaha

\section{Penelitian Sebelumnya}

Beberapa penelitiaan yang pernah membahas mengenai konsep ini dijelaskan pada tabel 1 . 
METODE PENELITIAN

Pengumpulan Data

Penelitian ini bersifat kuantitatif dengan menggunakan instrumen kuesioner untuk pengumpulan data. Sebanyak 35 responden (7 indikator dikali 5) yang merupakan mahasiswa dan fresh graduate sebagai kelompok muda yang diteliti dalam penelitian ini. Terdapat indikator yang digunakan dalama kuesioner yang ditanyakan kepada para responden.

\section{Pengolahan Data}

Penelitian ini akan menggunakan aplikasi SPSS 22 untuk mengolah data. Dengan menggunakan angka galat sebesar 5\%, beberapa uji akan dilakukan pada penelitian ini yaitu uji kesahian dan kehandalan, uji asumsi klasik, dan koefisien determinasi dan uji hipotesis.

\section{HASIL DAN PEMBAHASAN \\ Profil Responden}

Tabel 1 menjelaskan bahwa sebanyak 40 persen (14 responden) dalam penelitian ini adalah responden dengan gender laki-laki sedangkan sisanya 60 persen (21 responden) adalah dengan gender perempuan.

Tabel 3. Profil Responden

\begin{tabular}{lll}
\hline Gender & Frequency & $\begin{array}{l}\text { Valid } \\
\text { Percent }\end{array}$ \\
\hline Laki-laki & 14 & 40 \\
\hline Perempuan & 21 & 60 \\
\hline \multicolumn{2}{l}{ Sumber: Hasil Pengolahan SPSS 22, $(\mathrm{n}=35)$}
\end{tabular}

Uji Kesahian \& Kehandalan

Berdasarkan hasil olahan, dijelaskan bahwa angka cronbach's alpha sebesar 0,835 yang dapat mengartikan bahwa item yang digunakan handal. Pada tabel 2 dijelaskan bahwa kreativitas dan kenda berada di bawah angka 0,325 sehingga harus dibuang dari daftar item karena tidak memenuhi syarat kesahian.

Tabel 4. Hasil Uji Kesahian

\begin{tabular}{lll}
\hline \multicolumn{1}{c}{ Item } & Corrected Item Total Correlation & Keterangan \\
\hline Kreativitas & 0,397 & Sahih \\
\hline Kendali Diri & 0,512 & Sahih \\
\hline Norma Sosial & 0,575 & Sahih \\
\hline Keberanian & 0,639 & Sahih \\
\hline Keputusan & 0,393 & Sahih \\
\hline Rencana dalam waktu dekat 1 & 0,673 & Sahih \\
\hline Rencana dalam waktu dekat 1 & 0,616 & Sahih \\
\hline Kecenderungan Bertindak Total & 0,801 & Sahih \\
\hline Keinginan Berwirausaha Total & 0,734 & Sahih \\
\hline
\end{tabular}

Sumber: Hasil Pengolahan SPSS 22, $(n=35)$

Uji Normalitas

Dari gambar 2 dijelaskan bahwa tampilan Normal P-P Plot Regression Standardized memperlihatkan bahwa titik-titik menyebar di sekitar garis diagonal sehingga analisis regresi layak digunakan

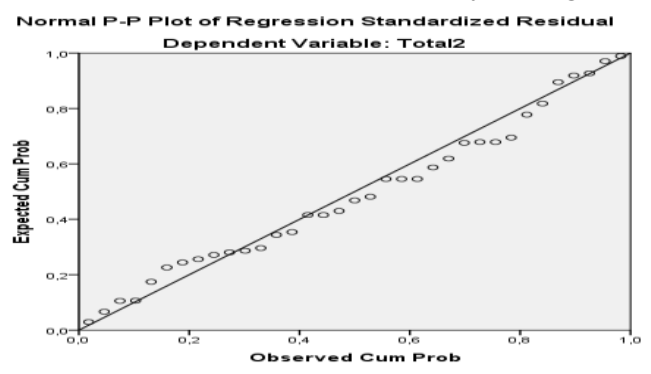

Gambar 2. Uji Normalitas Dengan Grafik

Sumber: Sumber: Hasil Pengolahan SPSS 22, $(n=35)$ 
Uji Multikolinieritas

Hasil ini menunjukkan bahwa nilai Variance Inflation Factor (VIF) tidak melebihi angka 10 yang berarti tidak terjadi gejala multikolinieritas terhadap model regresi yang terbentuk.

Tabel 5 Uji Multikolinieritas (VIF)

\begin{tabular}{l|l}
\hline \multicolumn{2}{l}{ Collineartity Statistics } \\
\hline Keterangan & VIF \\
\hline KW1 & 1,235 \\
\hline KW3 & 1,750 \\
\hline KW4 & 1,569 \\
\hline
\end{tabular}

Sumber: Hasil Pengolahan SPSS 22, $(n=35)$

Uji Heteroskedastisitas

Gambar 3 menjelaskan hasil uji heteroskedastisitas dengan metode grafik tidak membentuk sebuah pola (bergelombang, melebar kemudian menyempit), oleh karena itu maka pada data tersebut tidak terjadi heteroskedastisitas

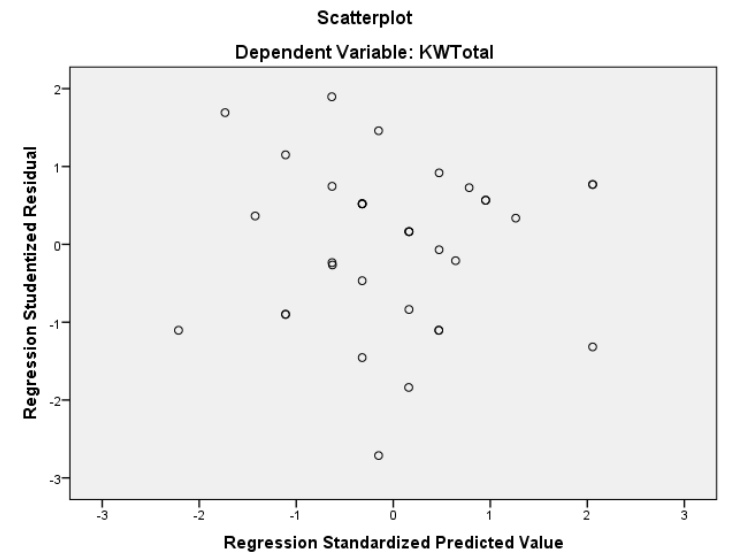

Gambar 3. Uji Heteroskedastisitas Dengan Grafik

Sumber: Sumber: Hasil Pengolahan SPSS 22, $(n=35)$

\section{Regresi Linier Berganda}

Hasil dari tabel 6 membentuk persamaan regresi sebagai berikut: $\quad Y=\mathbf{5 , 7 7 1 +}$

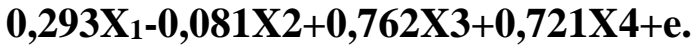

Tabel 6 menjelaskan bahawa korelasi berganda antara kreativitas, kendali diri, norma sosial dan keberanian mengambil risiko terhadap keinginan berwirausaha adalah sebesar 0,583 . Sementara koefisien determinasi sebesar 0,252 yang berarti bahwa variasi keinginan berwirausaha dapat dijelaskan oleh variasi kreativitas, norma sosial, dan keberanian dalam mengambil risiko sebesar 25,2 persen.

Tabel 6. Hasil Regresi Linier Berganda

\begin{tabular}{ll}
\hline Model & \\
\hline Constant & 5,771 \\
\hline Kreativitas & 0,293 \\
\hline Kendali diri & $-0,081$ \\
\hline Norma Sosial & 0,762 \\
\hline Keberanian & 0,721 \\
\hline \multicolumn{2}{l}{ Sumber: Hasil Pengolahan SPSS 22, $(\mathrm{n}=35)$}
\end{tabular}




\section{Tabel 7 . Koefisien Determinasi \\ Model Summary \\ $\boldsymbol{R} \quad$ Adjusted $R$ Square \\ $0,583 \quad 0,252$ \\ Sumber: Hasil Pengolahan SPSS 22, $(\mathrm{n}=35)$}

\section{Uji Hipotesis}

Dapat dilihat bahwa nilai $\mathrm{F}$ hitung sebesar 0,004 dimana nilai ini lebih kecil dari 0.05 . Hal ini dapat diartikan bahwa kreativitas, kendali diri, norma sosial, dan keberanian mengambil risiko secara bersama mampu menjelaskan perubahan pada keinginan berwirausaha atau dengan kata lain model dinyatakan fit. Hasil ini sesuai dengan penelitian yang dilakukan oleh Ahmad, Ramayah, \& Tuan Muda (2013).

Selanjutnya tingkat kesalahan pada nilai kreativitas yang diperoleh yakni sebesar 0,794 dengan nilai sig 0,433 atau lebih besar dari 0,05 maka kreativitas (X1) tidak berpengaruh terhadap keinginan berwirausaha (Y). Hasil ini menolak hasil penelitian Ahmad, Ramayah, \& Tuan Muda (2013). Besarnya tingkat kesalahan pada kendali diri yang diperoleh yakni sebesar -0,222 dengan nilai sig 0,825 atau lebih besar dari 0,05 maka norma sosial (X2) tidak berpengaruh terhadap keinginan berwirausaha (Y). Hasil ini menolak hasil penelitian Ahmad, Ramayah, \& Tuan Muda (2013). Besarnya tingkat kesalahan pada nilai norma sosial yang diperoleh yakni sebesar 2,170 dengan nilai sig 0,038 atau lebih kecil dari 0.05 maka norma sosial (X3) berpengaruh terhadap keinginan berwirausaha (Y). Hasil ini sesuai hasil penelitian Ahmad, Ramayah, \& Tuan Muda (2013). Besarnya tingkat kesalahan pada nilai keberanian dalam mengambil risiko yakni sebesar 1,955 dengan nilai sig 0,060 atau lebih besar dari 0,005 maka keberanian dalam mengambil risiko (X4) tidak berpengaruh terhadap keinginan berwirausaha (Y). Hasil ini menolak hasil penelitian Ahmad, Ramayah, \& Tuan Muda (2013).

Tabel 8. Uji Hasil Uji Hipotesis

\begin{tabular}{|c|c|c|c|}
\hline Uji Hipotesis & $t$ & $\boldsymbol{F}$ & sig \\
\hline \multicolumn{4}{|l|}{ Uji-t } \\
\hline Constant & 3,103 & & 0,004 \\
\hline Kreativitas & 0,794 & & 0,433 \\
\hline Kendali Diri & $-0,222$ & & 0,825 \\
\hline Norma Sosial & 2,170 & & 0,038 \\
\hline Keberanian & 1,955 & & 0,060 \\
\hline Uji-F & & 3,865 & 0,012 \\
\hline
\end{tabular}

\section{Simpulan \& Saran \\ Simpulan}

Berdasarkan penjelasan di atas, maka dapat simpulan dari penelitian ini adalah sebagai berikut:

1. Keinginan berwirausaha pada kelompok muda tidak dipengaruhi secara parsial oleh daya kreativitas individu

2. Keinginan berwirausaha pada kelompok muda tidak dipengaruhi secara parsial oleh kendali diri

3. Keinginan berwirausaha pada kelompok muda dipengaruhi secara parsial oleh norma sosial yang berlaku
4. Keinginan berwirausaha tidak dipengaruhi secara parsial oleh keberanian mengambil risiko

5. Keinginan berwirausaha dipengaruhi secara bersama oleh kreativitas, kendali diri, norma sosial dan keberanian mengambil risiko pada kelompok muda

\section{Saran}

Berdasarkan simpulan di atas, maka saran pada penelitian ini adalah sebagai berikut:

1. Pada faktor kreativitas, pengukuran pada spesifikasi item bidang yang diminati dirasa perlu untuk ditanyakan 
guna memberikan keterkaitan lebih tepat terhadap faktor kreativitas, misalnya kreativitas dalam hal kemampuan dalam memasarkan produ/jasa yang unik, membuat metode pembayaran yang unik, dan sebagainya.

2. Kendali diri merupakan faktor yang memiliki ukuran yang berbeda satu dengan yang lainnya. Oleh karena itu disarankan penggunaan pernyataan kencenderungan individu dipengaruhi oleh faktor dominan pihak mana (keluarga, teman,, atau tidak sama sekali).

3. Keberanian mengambil risiko pada kelompok muda sepertinya dapat dibuat lebih spesifik pada ketertarikan bidang wirausaha yang diinginkan, misalnya ketertarikan pada pilihan bidang seperti ritel bahan pokok, tata busana, perangkat gawai, penyelenggara kegiatan dan sebagainya. Hal ini akan memberikan gambaran yang lebih jelas terhadap tindakan keberanian mengambil risiko pada bidang yang dipilih.

\section{Daftar Pustaka}

Ahmad, N. H., Ramayah, T., \& Tuan Muda, S. A. (2013). Unlocking The Entrepreneurial Propensity Among Prime-Age Malayasian: A Multi-Ethnic Analysis. ResearchersWorld -Journal of Arts, Science \& Commerce , 4 (1), 1-6.

Ahmed, I., Nawaz, M. M., Ahmad, Z., Shaukat, M. Z., Usman, A., Rehman, W., et al. (2010). Determinants of students entrepreneurial career intentions: Evidence from business graduates. European Journal of Social Sciences , 15 (2), 14-22.

Alves, J. E., Cavenaghi, S., \& Martine, G. (2013). Population and Changes in Gender Inequalities in Latin America. the XXVII CONFERENNCIA DA IUSSP. Busan.

Amorós, J. E., Bosma, N., Kelley, D. J., \& Association, G. E. (2011). Global Entrepreneurship Monitor: 2010 Global Report. Fribourg: Institute for
Entrepreneurship \& Small and Medium Size Enterprises.

Arrighetti, A., Fabio, L., \& Lasagni, A. (2014). Intangible assets and firm heterogeneity: Evidence from Italy. Research Policy, 43, 202-213.

Bessant, J., \& Tidd, J. (2011). Innovation And Enrepreneurship (2nd ed.). West Sussex: John Wiley \& Sons Ltd.

Carr, J. C., \& Jennifer, S. M. (2007). Prior family business exposure as intergenerational influence and entrepreneurial intent: A Theory of Planned Behavior approach. Journal of Business Research , 60, 1090-1098.

Chen, S.-C., Jing, L.-L., \& Sung, M.-H. (2012). University students personality traits and entrepreneurial intention: Using entrepreneurship and entrepreneurial attitude as mediating variable. International Journal of Economic Research , 3 (3), 76-82.

Dana, L. P. (2011). World Encyclopedia of Entrepreneurship. Northampton: Edward Elgar Publishing Limited.

Elmansori, E. (2014). Business Incubators in the Arab World. World Journal of Science, Technology and Sustainable Development , 11 (4), 282-293.

Furstenberg Jr, F. F. (2010). On a New Schedule: Transitions to Adulthood and Family Change. The Future of Children , 20 (1), 67-87.

Gonzales, R. G. (2011). Learning to be illegal undocumented youth and shifting legal contexts in the transition to adulthood. American Sociological Review , 76 (4), 602-619.

Hisrich, R. D., Peters, M. P., \& Shepherd, D. A. (2010). Entrepreneurship (8th ed.). Singapore: McGraw-Hill/Irwin.

Krueger, N. F., Reilly, M. D., \& Carsrud, A. L. (2000). Competing Models of Entrepreneurial Intentions. Journal of Business Venturing , 411-432. 
Liñán, F. (2004). Intention-Based Models of Entrepreneurship Education. Small Business Economics , 3, 11-35.

Lubis, R. L. (2015). The "Triple-I" Learning Model of Entrepreneurship Education in Indonesia: Where Do We Go From Here? International Journal of Arts \& Sciences , 8 (7), 233-264.

Malik, B. K. (2015). Youth Development in India: Does Poverty Matter? Malik SpringerPlus , 4 (613), 1-10.

Money, U. (2016). The Creation and Development of Job in Nigeria: Entrepreneurship Enlightment. Researchers World - Journal of Arts, Science \& Commerce , 3 (1), 96-100.

Nasirifard, E., Allahyari, M. S., \& Masouleh, D. Z. (2015). An analysis of rural cooperatives manager's entrepreneurial spirit in Guilan Province. Science \& Research Quarterly Journal of Cooperation and Agriculture , 3 (12), 133155.

Shal, F. K., Amar, T., Allahyari, M. S., \& Ramezani, B. (2016). Socio-economic Factors Affecting Spatial Planning of Entrepreneurship in Rural Area (Evidence from Masal County, Iran).
Journal of Current Research in Science , 4 (1), 40-46.

Shook, C. R., \& Britianu, C. (2008). Entrepreneurial Intent In a Transitional Economy: An application of the Theory Planned of Behavior to Romanian Students. International Entrepreneurship Management Journal , 6 (3), 231-247.

Shook, C., \& Bratianu, C. (2010). Entrepreneurial intent in a transitional economy: an application of the theory of planned behavior to Romanian students. Management Journal , 231-247.

Sipitanou, A. A., \& Papagiannis, G. D. (2013). Education, Entrepreneurship and Entrepreneurial Activation: A Challenge for All. International Journal of Arts \& Sciences , 6 (2), 139-149.

Stromquist, N. P., \& Monkman, K. (2014). Globalization and Education: Integration and Contestation Across Cultures. R\&L Education.

Udih, M. (2016). The Creation and Development of Job in Nigeria: Entrepreneurship Enlightment. Researchers World - Journal of Arts, Science \& Commerce , 3 (1), 96-100. 